\section{The Issue Of Lingvopoetics And Poetic} Individuality

\section{G open ACCEss}

The American Journal of

Social Science And

Education Innovations

JULY 2020

Page No.: 134-144

Volume-II Issue-VII

PUBLISHED: 30 JULY 2020

www.usajournalshub.com/inde

x.php/tajssei

Copyright: Original content

from this work may be used

under the terms of the

Creative Commons Attribution

4.0 licence.

\title{
Abstract
}

This article discusses the language of the literary work, its study, the writer's use of words, the reflection of words in the writer's work in new and extraordinary meanings, and ultimately the emergence of poetic individuality.

Keywords: language of fiction, writer's style, poetic individuality, linguo-poetics.

\section{Introduction}

Analyzing the language of artists' works is one of the ways to study Uzbek language in depth. If we take a look at the history of this good work, which began in the 30s and 40s of the last century, we can see that the scope of research in this field has gradually expanded, and the scientific basis has been strengthened. This experiment, initiated by the great intellectuals of Uzbek people Oybek, Ayub Gulam, has reached the level of its linguo-poetic research at the present stage of development of Uzbek linguistics, that is, the high value of language - the artistic and aesthetic impact on the listener and reader. The show began to be explored on the basis of knowledge and skills accumulated over 
thousands of years, as well as on the basis of modern methods of analysis, with a deep understanding of the possibilities as a supreme expression of the unique emotions hidden in the depths of an infinite creation. As the human factor and interests have risen to unprecedented heights since independence, these studies have become based on anthropocentric, cognitive, and linguo-cultural principles.

We compare Uzbek language to the ocean, and this is the right thing to do. Because just as only a fraction of our wealth is visible on the surface of the ocean and most of it is hidden in its depths, very little of our linguistic richness is on the surface, that is, known and understood by most of us. The main part is hidden.

Although everyone has the right to use the language, the level of use is not the same. If the average consumer of language uses only the words that are necessary for everyday life, located on the surface of the ocean of language, those who are engaged in artistic creation will be able to find even the most precious gems in the depths of this ocean and have the ability to pick up a necklace. Therefore, learning the language skills of artists is like rediscovering the riches of our native language and discovering new aspects of the laws of our language in the field of art.

\section{The Main Findings And Results}

There is no work of art without ideas. It expresses certain spiritual and enlightenment thoughts and feelings, whether small or large. For us, the choice of the means of expression, the reflections in the process of expression, the nuances of meaning arising from their placement in the structure of the text, the formal changes aimed at the aesthetic effect are important. Because it is only in these cases that the poet's individuality, his ability to think artistically, to understand the mysteries of the native language are revealed.

It is absolutely impossible to imagine the formation of a literary text as a work of art and poetry without linguistic material. It is natural for the author to take a unique approach to the use of this unique material. Each poet and writer's work and attitude to language is individual. Consequently, the use of linguistic means in the text of one artist's work never corresponds to the style of another artist. The study of his work in the system 
of poetic individuality allows us to draw certain conclusions not only about the creative style of the poet and writer, but also about his contribution to the development of the native language.

Although the language of fiction has been studied in a variety of ways and a great deal of scientific research has been done on the subject, the subject has not lost its relevance and novelty today. As long as works of art are created, the study of their language and creative poetic skills will continue. After all, the writer's individual style is reflected primarily in his language.

It is worth quoting the famous Russian writer K. Fedin: "It is necessary to start with the language of the writer's skill. Language will always be the main material of a work. Fiction is the art of language [13.133-134].

H. Gulam's comments on this issue are also noteworthy: "The work on language is the basis of the writer's work. Once the theme has been chosen, the purpose has been determined, the characters, their portraits and characters have been vividly imagined, and the writer takes the pen in his hand and begins the work, a continuous, arduous, endless work on the word begins. In this work, the author diligently collects sentences from the vocabulary he has accumulated over the years. Both the richness of thought and the hidden side notebooks on the desks are activated. ... I need a word! We need a new, unspoken word, which will serve to reveal the story, the inner world of the protagonist, his delicate character, and will be able to amaze the reader at once! .. Find the key to the language in your work a writer who knows can create fluently in his own style. There is no more complex art in the world than language" [15. 171-172].

The formation of the linguopoetic direction in the study of poetry in the early twentieth century is associated with the names of Yu. Tinyanov, V. Zhirmunsky, R. Jacobson, B. Eichenbaum and other famous scientists, - writes M. Stepanov. "Since then, poetry has ceased to be, first and foremost, an aesthetic phenomenon in the scientific sense". The aesthetic function of poetry has taken a back seat. The structure of the relationship between poetry and language, the interaction of poetry and language came to the fore [12.4].

In fact, R. Jacobson was one of the founders of the science of linguo-poetics and 
made a significant contribution to its development. The scholar's theoretical views on this subject are mainly concentrated in his work "Problems of Poetics" (1987). The scholar wrote: "Poetics is the linguistic study of the poetic function of verbal information in general and poetry in particular" [14. 9].

Academician V.V. Vinogradov is undoubtedly one of the cornerstones of stylistics and linguopoetics in world linguistics. V. Vinogradov «Stylistics. Theory of poetic speech. Poetics", first of all, pointed out the subject of linguostylistics and linguopoetics, their similarities and differences: "... It is necessary to limit at least three different areas of research. This is, firstly, the stylistics of language or structural stylistics as a "system of systems", secondly, the stylistics of speech, that is, the various forms and situations of social use of language, and thirdly, the stylistics of fiction. The theory and history of poetic speech and poetics are the next ones" [4. 5]. V. Vinogradov also notes that in this work the approaches of literary and linguistic and other art criticism are combined in the framework of poetics. "Poetics is based on and to some extent based on poetic discourse, and the structural elements of a literary work cannot be limited to the means and principles of pure linguistic analysis, but only to the categories and forms related to the language and speech of artistic construction. It is enriched by general theories and concepts of art criticism and literary criticism. Thus, in the field of poetics, the study of the structure of literary and artistic works combines linguistic, aesthetic and stylistic, as well as literary and artistic methods "[4. 185]. Therefore, the development of the writer's skills from work to work, the process of self-reflection in the works, the role of the writer and his works in the literature are based on linguopoetic analysis, which leads to a successful solution of the problem in both literature and linguistics.

Along with $V$. Vinogradov, there are many views on the subject in linguistics and literature. For example, acad. "The aim of the linguistic study of a literary text is to show the ideological content of a literary work and the emotional content associated with it", said Prof. L. Shcherba. Tomashevsky said that a narrow range of linguistic knowledge was not enough to understand a literary work. R. Budagov, in his article "What can the science of language give to the science of literature" says that these two sciences give each other a lot [2. 20]. 
B. Sarimsakov agrees with this opinion and writes the same. "... Whether linguists or literary critics, they must unite in linguo-poetics, in matters of art (figurativeness), so that they become true philologists. Problems of art are purely philological problems" [11. 27].

I. Mirzayev emphasizes that linguo-poetics is recognized as a field that can restore the integrity of philology, the need to increase and strengthen research in this area, and writes: on the contrary, they apply their achievements to the analysis of the text, and thus, on the one hand, strengthen the student's knowledge of these disciplines, and, on the other hand, in it a real philologist (his opinion is expressed orally and in writing) forms clearly, concisely, succinctly, logically consistent narration, oratory) skills. The only way to achieve this is through philological (linguo-poetic) analysis of the text" [9. 82; 10. 22]. His views are also noteworthy: "Linguo-poetics works in a manner similar to the dichotomy of language and speech, covering not only the general problems of language, but also the tasks of network sciences, and thus provides ample opportunities to ensure the unity of philology" [10. 22]. Poetics is the starting point for the interpretation of poetic texts. This, of course, does not preclude them from being analyzed in any other way. "The task of the linguist who analyzes the poetic text is to study' literary 'or, in other words, the transformation of speech into a poetic work and the system of receptions that carry out this transformation [14]. Linguo-poetics helps to identify the specificity of the work under study and provides material for a wide range of generalizations.

O. Akhmanova, one of the leading scientists of the XX century, her students $V$. Zadornova and A. Lipgart studied the issues of aesthetic influence of fiction and made a great contribution to the formation of linguo-poetics as a separate philological field.

In her doctoral dissertation, V. Zadornova studied the methodology of linguo-poetic analysis and its differences from observations on the stylistic description of works of art and expressed the opinion "Linguistic analysis of the text is aimed not at identifying those or those stylistic methods, but at interpreting the aesthetic effect of an artistic work as an example of creativity" and said the following about the subject, goals and objectives of linguo-poetics: "The linguo-poetic study of a text is not just about identifying a unit of language, but about interpreting the aesthetic impact of a work of art through words" [5. 
61]. In general, V. Zadornova assessed the subject of linguo-poetics as a set of language tools that provide the writer's aesthetic influence in the work of art, helping to reveal the ideological and artistic purpose.

One of the most recent sources on the theory of linguo-poetics is A. Lipgart's Fundamentals of Linguo-poetics. This work is based on in-depth analysis of the subject, goals and objectives of the field of linguo-poetics, which emerged between linguistics and poetics. This is evidenced by the fact that more than 400 scientific sources on the subject, published in different languages of the world, have been studied, and the views of wellknown Russian philologists such as V. Vinogradov, V. Tomashevskiy, A. Potebnya, R. Jacobson, O. Akhmanova, I.Galperin, M.Baxtin, V.Zadornova are the basis for analysis.

Academician V. Vinogradov's views, which served as a methodological basis for the study of the language of fiction in Uzbek linguistics, also served as a basis for A. Lipgart. The author acknowledges that the linguo-poetic study of the literary text is inextricably linked with the research of $\mathrm{V}$. Vinogradov, states that the linguo-poetic comments on the works of all classics of Russian literature belong to his pen, and analyzes his views on this subject in section "Communication/message/influence on the nature of the trichotomy category of language function" of the book. According to the scientist, this trichotomy differs fundamentally from other classifications of language by its categorical nature and can be applied to all elements of language. This function of language is manifested in functional styles. If there is a violation of the norm of this task somewhere, then it is assumed that the language units will give some additional efficiency [6. 13, 39-45].

Commenting on the teachings of V. Vinogradov, A. Lipgart emphasizes that the communicative function of language makes extensive use of lexical level capabilities in the semantic plan and is mainly in the style of speech, while the message-information function is primarily based on the logic of expression and is built on a semiotic basis appears more in scientific texts. Language can be deformed as it moves to perform its function, and some language units become actualized and demonstrate their potential. Fiction is a shining example of the power of language.

A. Lipgart describes linguo-poetics as follows: "Linguo-poetics is a branch of philology in which the use of methodically marked units in the literary text in the context 
of linguo-poetics, their orientation to the aesthetic effect in the text, and for this purpose is to be used in the semantic structure of the text" [5. 18-19].

So what do we know about the aesthetic function of language? The concept of the aesthetic function of language was originally used as a poetic task in R. Jacobson's Linguistics and Poetics. The third task in the communication-message-influence triad, which represents the social nature of language, also encompasses the power of aesthetic influence. All the linguistic tools used in fiction can serve to enhance the aesthetic dimension of fiction by meeting the requirements of language culture. So, along with other functions of language, the aesthetic function is also a very important category. In the words of N. Mahmudov, "the aesthetic task facilitates the main communicative function of language, enriches its possibilities. Language and speech, with the same aesthetic function, express the power of expressiveness and influence" [7. 47-51]. Therefore, one of the tasks of studying the language of a work is to study the same aesthetic value of the language. From the above-mentioned opinions of researchers in the field, it is clear that the main object of study of linguo-poetics is the literary text will be studied.

In Uzbek philology, dealing with this problem has historical roots. For example, Alisher Navoi in his "Muhokamat ul-Lugatain" and other works six centuries ago proved both the theoretical and practical significance of the visual potential of the Uzbek literary language and its importance for poetry [1. 103-132].

Indeed, language, an important symbol of human existence and existence, has been fulfilling its social function perfectly since the beginning of human existence as a community, as we can see in the case of every developed language in the world, including Uzbek is possible.

The formation of the Uzbek language, its role in the historical development of the Turkic peoples and our nation has been studied in depth by scientists in recent centuries, and these studies also cover the problems of artistic language, which is a great example of language use.

The concept of writer's style, which has long been studied in philology, essentially refers to the creative individuality. In this sense, the term poetic individuality, which is actively used in modern philological research, is not a novelty for science, but its 
renaming.

Learning the language of a work of art is a complex process. He spoke about the advantages of studying the "artistic material" of a literary text in its time, its artistic and aesthetic impact on the reader. V. Vinogradov's "On the language of fiction" (M., 1959), "Poetics and its relation to the theory of linguistics and literature" ("Language issues", 1962, №5), "Stylistics, the theory of poetic speech. Poetics "(M., 1969)," On the Theory of Artistic Speech" (M., 1971), "Problems of Russian Stylistics" (M., 1981) are directly devoted to the problems of the language of fiction and are still present in the former Soviet Union and today also serves as a methodological basis in the field of linguistics of the Commonwealth of Independent States, including Uzbek linguistics. Therefore, many solutions to the problems of poetic individuality can be found in these works.

The concept of the writer's individual style was also theoretically evaluated by $\mathrm{V}$. Vinogradov. In "On the Language of Fiction" the scholar emphasizes that the "language" ("style") of the work of art and the "language" ("style") of the writer are among the central problems of the study of the language of fiction. 'The process of formation and emergence of verse-creative thought, on the other hand, can and should be studied as a legitimate part of the general development of folk oral art and as a clear historical fact [3. 84, 170-171].

As $\mathrm{V}$. Vinogradov noted, the problem of individual style cannot be studied in isolation from the laws inherent in the development of literary styles. Since the individual style of the writer is a system of individual-aesthetic use of means of expression typical of the creative period of fiction, the concept of individual style should be covered in conjunction with other problems of the language of fiction [3. 85-86, 87].

Linguopoetic research is also directly related to the analysis of the individual style of poets and writers, and this concept is recognized as one of the main categories of literary text research.

The artist's artistic skill can also be interpreted as a language skill. The deeper his knowledge of the language and the stronger his ability to use it, the more literary a work will undoubtedly be, no matter what genre it is written in.

Of course, there are criteria for determining the poetic individuality of a writer. This 
unique style is illustrated by comparing his works in one or more genres or at least those works with other artists, as well as with works of a certain period.

Despite the similarities in the use of thematic and linguistic tools, the uniqueness of each artist's approach to linguistic facts is the linguistic factor that determines their individuality.

Elements of language appear in different situations in the formation of a literary text. The infinity of linguistic combinations in language makes this possible. But that doesn't negate the tradition of use. In any case, each poet or writer follows a unique path in the use of language material, and this path defines the creative individual. Ultimately, the demand and necessity of selective use of language elements that define style are also considered within the framework of these criteria of individuality.

The need for figurative expression of thoughts and feelings in art motivates the creator to work on the language of the text, on each element in it.

The process of selecting language elements that are considered hard work also shapes the individual style of the creator. It is such a complex and intangible process that the creator selects and uses the elements of language based on knowledge, worldview, cognition, perception of the world, in short, all the defining features. In this way, certain words, phrases, or speech devices in a language become factors that determine the individual style of the creator.

There are many factors that determine the poetic individuality of a poet or writer, such as the predominance of a particular idea and harmony with other artists, tradition and innovation, uniqueness and denial of existing traditions, responsiveness to time and politics. These factors are studied in the literary aspect of poetic individuality. But it lacks an important factor for us to imagine a holistic view of the creative individuality. This is a linguo-poetic factor.

Linguo-poetic research, of course, provides a wealth of information about the aesthetic value of language tools in literary texts and leads to certain scientific conclusions. However, V. Vinogradov's "The style of all the works of the writer, with all the complexity and originality of their structure as a whole artistic integrity, can be given a material about the individual style of the writer, the conditions of its formation" [3. 85- 
$166]$, it is necessary to strengthen the theoretical basis and clarify the methodology of research in this field in Uzbek philology, in particular in linguo-poetics.

\section{References}

[1]. Alisher Navoi. Muhokamat ul-Lugatain. Works. Fifteen volumes, 14 volumes. Tashkent. 1967.

[2]. Budagov R.A. (1980) Philology and culture. - Moscow: MGU.

[3]. Vinogradov V.V. (1959) About the language of fiction. - Moscow. Fiction Writing.

[4]. Vinogradov V.V. (1969) Stylistics, theory of poetic speech. Poetics. - Moscow.

[5]. Zadornova V.Y. (1992) Verbal and artistic work in different languages as a subject of linguo-poetic research: Doctor of Philological Sciences. Diss. - Moscow.

[6]. Lipgart A.A. (2016) Basics of linguo-poetics. - Moscow.

[7]. Mahmudov N. (2006) Speech culture and aesthetic function of language // Philological issues. - Tashkent. №2 (11). - pp. 47-51.

[8]. Mirzaev I. (2002) Linguistic poetics and its role in philological analysis // Current issues of linguistics. Collection of scientific articles. -Tashkent: University - p. 22.

[9]. Mirzaev I. (2006) On the fact that linguo-poetic analysis is a primary factor in the preparation of philological-creative thinking // Current issues of linguistics. Collection of scientific articles. Volume III. - Tashkent: Publication of the National University of Uzbekistan. - pp. 81-83.

[10]. Mirzaev I. (2002) Linguistic poetics and its place in philological analysis. // Current issues of linguistics. Collection of scientific articles. - Tashkent: University. - pp. 20-23.

[11]. Sarimsakov B. (2004) Fundamentals and criteria of art. - Tashkent. - p. 27.

[12]. Stepanov M. (2007) Denotation and connotation in poetic discourse: Avtoref. Dis ... Candidate of Philological Sciences. - Moscow. - p.4

[13]. Fedin K. (1960) On skill. About artistic creation. A collection of speeches and articles by writers. -Tashkent. - pp. 133-134.

[14]. Jacobson R. (2004) Problems of Poetics. Translated by I. Mirzayev. - Samarkand: Samarkand State University Edition. - p. 9. 
[15]. Ghulam H. (1985) The Mirror of Time. (Problems of literary language) // Sharq yulduzi. №3, - pp. 171-172.

[16]. Khamidov Kh.Kh., Ismatullayeva N.R., Rasulova Z.Kh., Karimova D.E. The Issues of Word Choice in Fiction Translation. International Journal of Psychosocial Rehabilitation, 24 (04), 2020. - pp. 6660-6668. DOI: 10.37200/IJPR/V24I4/PR2020478 